\title{
Prior exposure of Arabidopsis seedlings to mechanical stress heightens jasmonic acid- mediated defense against necrotrophic pathogens
}

Eric Brenya ${ }^{1,2}$, Zhong-Hua Chen $^{1,3}$, David Tissue ${ }^{1}$, Alexie Papanicolaou ${ }^{1}$ and Christopher lan Cazzonelli ${ }^{1 *}$ (D)

\begin{abstract}
Background: Prolonged mechanical stress (MS) causes thigmomorphogenesis, a stress acclimation response associated with increased disease resistance. What remains unclear is if; 1) plants pre-exposed to a short period of repetitive MS can prime defence responses upon subsequent challenge with necrotrophic pathogens, 2) MS mediates plant immunity via jasmonic acid (JA) signalling, and 3) a short period of repetitive MS can cause longterm changes in gene expression resembling a stress-induced memory. To address these points, 10-days old juvenile Arabidopsis seedlings were mechanically stressed for 7-days using a soft brush and subsequently challenged with the necrotrophic pathogens, Alternaria brassicicola, and Botrytis cinerea. Here we assessed how MS impacted structural cell wall appositions, disease symptoms and altered gene expression in response to infection.
\end{abstract}

Results: The MS-treated plants exhibited enhanced cell wall appositions and jasmonic acid (JA) accumulation that correlated with a reduction in disease progression compared to unstressed plants. The expression of genes involved in JA signalling, callose deposition, peroxidase and phytoalexin biosynthesis and reactive oxygen species detoxification were hyper-induced 4-days post-infection in MS-treated plants. The loss-of-function in JA signalling mediated by the JA-insensitive coronatine-insensitive 1 (coil) mutant impaired the hyper-induction of defense gene expression and promoted pathogen proliferation in MS-treated plants subject to infection. The basal expression level of PATHOGENESIS-RELATED GENE 1 and PLANT DEFENSIN 1.2 defense marker genes were constitutively upregulated in rosette leaves for 5 -days post-MS, as well as in naïve cauline leaves that differentiated from the inflorescence meristem well after ceasing MS.

Conclusion: This study reveals that exposure of juvenile Arabidopsis plants to a short repetitive period of MS can alter gene expression and prime plant resistance upon subsequent challenge with necrotrophic pathogens via the JA-mediated COl1 signalling pathway. MS may facilitate a stress-induced memory to modulate the plant's response to future stress encounters. These data advance our understanding of how MS primes plant immunity against necrotrophic pathogens and how that could be utilised in sustainable agricultural practices.

Keywords: Mechanical stress, Necrotrophic pathogen, Jasmonic acid, Stress priming, Alternaria brassicicola, Botrytis cinerea

\footnotetext{
* Correspondence: c.cazzonelli@westernsydney.edu.au

${ }^{1}$ Hawkesbury Institute for the Environment, Western Sydney University,

Locked Bag 1797, Penrith, NSW 2751, Australia

Full list of author information is available at the end of the article
}

(c) The Author(s). 2020 Open Access This article is licensed under a Creative Commons Attribution 4.0 International License, which permits use, sharing, adaptation, distribution and reproduction in any medium or format, as long as you give appropriate credit to the original author(s) and the source, provide a link to the Creative Commons licence, and indicate if changes were made. The images or other third party material in this article are included in the article's Creative Commons licence, unless indicated otherwise in a credit line to the material. If material is not included in the article's Creative Commons licence and your intended use is not permitted by statutory regulation or exceeds the permitted use, you will need to obtain permission directly from the copyright holder. To view a copy of this licence, visit http://creativecommons.org/licenses/by/4.0/ The Creative Commons Public Domain Dedication waiver (http://creativecommons.org/publicdomain/zero/1.0/) applies to the data made available in this article, unless otherwise stated in a credit line to the data. 


\section{Background}

Mechanical stress induced by stamping on juvenile crops has been utilized for centuries by farmers in China and Japan in a practice called mugifumi to harden crops against biotic and abiotic stresses [1]. Prolonged MS induced by wind or touch can alter the plant cell wall by enhancing elastic resilience and flexural stiffness, culminating in a plant with shorter stature, reduced leaf size, and increased tensile strength; this acclimation response is known as thigmomorphogenesis [2, 3]. Prolonged MS-induced lignin, cellulose, phenylalanine ammonia-lyase, peroxidases, and reduced intracellular spaces to make it harder for pathogens to invade the plant cell [4-8]. A single event of MS from exogenous water spray to Arabidopsis seedlings growing in artificial media or the bending of leaves from soil grown plants, has been reported to cause large-scale differential gene expression of 10 and $2.5 \%$ respectively, in naïve Arabidopsis tissues [9, 10]. The majority of MS-responsive genes were implicated in cell wall modifications, hormone regulation, organelle, and calcium signalling, that collectively mediate stress acclimation responses in plants [9-12]. In the absence of MS, the expressions of most MS-responsive transcripts returned to their basal level of expression. However, some genes such as TOUCH transcripts ( $\mathrm{TCH} 3$ and TCH4) involved in calcium signalling and cell-wall modification remained responsive to MS, while others became desensitized to subsequent stimulation $[11,12]$. The rapid change in gene expression in response to a single stimulus of MS can provide a decreased sensitivity to prolonged MS and protect the plant from unnecessarily responding to repeated MS induced by wind or touch. The desensitisation of plants to repetitive MS could represent 'a memory' that enables them to cope with continued events of MS [13-15].

Plant immunity involves phytohormone biosynthesis and signalling, in particular JA has been extensively linked with plant defenses against necrotrophic infection. Naïve Arabidopsis plants subject to a transient $40 \mathrm{~s}$ of gentle leaf rubbing without overt tissue damage showed enhanced resistance to Botrytis cinereal, although this was independent of JA biosynthesis or signalling [8]. In contrast prolonged MS (14-days of touch) can enhance JA accumulation to induce thigmomorphogenesis, and also promoted resistance against $B$. cinerea in Arabidopsis [16]. Exogenous water spray will also transiently elicit a JA response that can last a few hours [9] and Arabidopsis mutants impaired in JA biosynthesis and signalling (allene oxide synthase, and myc2 myc3 myc4 triple mutant) were shown to prevent thigmomorphogenesis and/or the expression of some MS-inducible genes, thus implicating JA in MS-induced responses [9, 16]. JA signalling is restrained by JASMONATE-ZIM-
DOMAIN (JAZ) repressors that interact with the F-box protein COI1 (CORONATINE INSENSITIVE1), which is part of the SCF (Skp-Cullin-F-box) E3 ubiquitin ligase complex involved in the direct interaction with Jasmonyl-L-Isoleucine (JA-Ile)/Coronatine (COR) [17]. In response to stress, the COI1-JAZ co-receptor complex leads to the proteasome-dependent degradation of JAZ repressors and the release of MYC transcription factors that affect JA dependent processes. The loss-offunction mutation in COI1 abolishes the formation of the protein complex and JA responses required for wound- and jasmonate-induced transcriptional regulation of plant defense [18]. Additional signalling pathways involving other hormones such as gibberellins also facilitate MS-induced thigmomorphogenesis and stress acclimation in plants $[19,20]$. What remains unclear is if a short repetitive period of MS culminating in JA responses [9] can elicit defence against necrotrophic pathogen infection via a JA-dependent or JAindependent process.

Prolonged stress to plants, including salt stress, extreme temperature and pathogen infection can induce a 'memory' mediated by epigenetic processes to enhance the plants acclimation response to future stress encounters [21]. Reports indicate that MS-induced responses in Arabidopsis involve epigenetic modification such as histone methylation [22, 23]. However, whether MS application representing the first stress encounter by plant can induce stress memory or prime the plants' response to subsequent stress (pathogens or abiotic stress) is unknown. Priming is defined as the enhanced sensitivity and responsiveness of plants to stress as a result of prior experience that leads to increased resistance or tolerance to biotic and/or abiotic stress [24]. Priming provides plants with a beneficial advantage to respond faster and mitigate a subsequent stress. The priming phase occurs at the physiological, transcriptional, proteomic, metabolic and epigenetic levels as a warning signal to mount a stronger response that can persist through the plants' life cycle and in some cases can be inherited to the subsequent generation [24-26].

The effect of MS on plant defense has mostly been assessed utilising $B$. cinerea as the model necrotrophic pathogen via histochemical or phenotypic studies. However, the molecular mechanisms of MS-induced plant immunity, and if MS can prime defense responses, remains unclear. Here, we investigated if 10-days old juvenile Arabidopsis seedlings subject to 7-days of MS could prime defense against $A$. brassicicola infection. The genus Alternaria are important fungal pathogens that cause black spot disease in Brassica species, leading to a yield loss of more than $15 \%$ worldwide [27]. Infection by Alternaria brassicicola is characterized by dark brown lesions and a yellowish chlorotic halo 
surrounding a necrotic lesion on leaves [28]. A. brassicicola is a necrotrophic pathogen that requires mostly JA mediated defense and feeds on dead plant tissue in order to proliferate $[29,30]$.

We hypothesised that a short period of repetitive MS would enhance the plants' tolerance or resistance for several days post-stimulation by altering phytohormone accumulation, enhancing defense gene expression and cell wall secondary metabolites that promote plant defense. Here we show that plants subjected to a short period of repetitive MS primed a defense response against $A$. brassicicola in the WT, but not in the JAinsensitive mutant coi1-16, implicating JA in MSinduced immunity. Our study revealed that a nonchemical strategy such as MS can heighten plant defenses in seedlings and promote resistance against necrotrophic pathogens.

\section{Results}

A short period of MS induces defense-related metabolites Here, we investigated if a 7-day period of repetitive MS to wild type (WT) Arabidopsis seedlings can alter defense metabolites and induce thigmomorphogenesis. A single event of MS using a soft brush (10 s twice daily, $8 \mathrm{~h}$ intervals) to 10-days old juvenile Arabidopsis plants elicited high expression of TCH3 and TCH4 (XTH22) genes, which are involved in calcium signalling and cell wall modifications, respectively [31, 32]. The gene expression lasted up to $60 \mathrm{~min}$ (3-fold higher) or perhaps longer reaching a maximum peak at $30 \mathrm{~min}$ following MS (6- to 10-fold) (Fig. 1A). The 7-days of MS caused a significant reduction in the overall plant growth, evident by a 32 and $47 \%$ decrease in petiole length and rosette area respectively, compared to the unstressed (control) plants (Fig. 1B). Interestingly, MS caused a 35\% reduction in plant height despite MS being ceased before the emergence of the inflorescence stem (Fig. 1C). Therefore, a 7-day period of repetitive MS (herein referred to as a short period of MS) to juvenile seedlings induced thigmomorphogenesis in the absence of continued stimulation.

We next assessed MS effect on the accumulation of jasmonic acid (JA) and salicylic acid (SA) in MS and control plants using ultra-high-performance liquid chromatography-tandem mass spectrometry (UHPLCMS/MS). Samples were collected $30 \mathrm{~min}$ after 7-days of MS when thigmomorphogenesis was prominently evident as a phenotype. MS significantly upregulated JA levels ( 5-fold) and reduced SA (40\%) in MS-treated compared to control plants, revealing an antagonistic effect between JA and SA signalling (Fig. 1D). MS-treated and control plants were stained with phloroglucinol that revealed high lignin deposition (reddish precipitation) in the shoot meristem and midrib of MS-treated plants perhaps indicating a higher tensile strength induced by MS (Fig. 1E). These data show that a short period of MS can promote the accumulation of metabolites that mediate thigmomorphogenesis and pathogen defense.

\section{Mechanical stress enhances resistance against Alternaria brassicicola}

We questioned if 7-days of MS could enhance plant defense upon subsequent challenge with $B$. cinerea or Alternaria brassicicola. Leaves from MS-treated plants (the 5th, 6th, and 7th true leaves) were inoculated with $5 \mu \mathrm{l}$ of $B$. cinerea spores $30 \mathrm{~min}$ after the last stimulation. Leaves from MS-treated plants showed a reduced necrotic lesion area $\left(3 \mathrm{~mm}^{2}\right)$ confirmed by lactophenoltrypan blue (LPTB) stain compared to control plants (8 $\mathrm{mm}^{2}$ ) (Fig. 2A). Consistent with previous report [16], we show that a short 7-day period of MS can induce resistance (62.5\% less in lesion area; $48 \mathrm{~h}$ post-inoculation) in Arabidopsis against B. cinerea infection.

Five days post-inoculation with Alternaria brassicicola, the control plants showed enhanced leaf chlorosis (yellowing of cells due to chloroplast degradation) and a halo of necrotic lesion surrounding the initial inoculation site, revealing an incompatible interaction [33]. The rosette leaves from MS-treated plants did not display obvious signs of chlorosis or the halo of necrotic lesion (Fig. 2B). Staining of leaves with lactophenol trypan blue revealed that the pathogen was restricted to the initial spore inoculation site in MS-treated leaves (Fig. 2C). In control plants, the pathogen appeared to degrade tissues surrounding the inoculation site (Fig. 2B). Four- and sixdays post-inoculation, the lesion area was significantly larger in control plants $\left(5.2 \mathrm{~mm}^{2}\right.$ and $\left.11.9 \mathrm{~mm}^{2}\right)$ compared to MS-treated plants $\left(3.0 \mathrm{~mm}^{2}\right.$ and $6.7 \mathrm{~mm}^{2}$ ) (Fig. 2C). Therefore, a short period of MS can enhance defense against Alternaria brassicicola.

\section{Mechanical stress enhances cell wall compounds and primes plant defense}

Next, we probed whether MS enhances cell wall defenses (callose, lignin, camalexin, and ROS) to limit $A$. brassicicola proliferation. Analysis of callose which is a $(1,3)$ - $\beta$-glucan polymer that forms cell wall thickenings called papillae was enhanced in MS-infected leaves ( $>2$ fold deposition) compared to control-infected leaves. Callose deposition was confined to edges of the inoculation site in MS-infected leaves, whereas in controlinfected leaves callose spread outside the inoculation site in areas of pathogen migration (Fig. 3A). Five days after inoculation, transcript levels of callose-associated marker gene GLUCAN SYNTHASE-LIKE 6 (GSL6), was significantly upregulated (3.5-fold) in MS-infected compared to control-infected leaves (Fig. 3A). The PEROXIDASE 


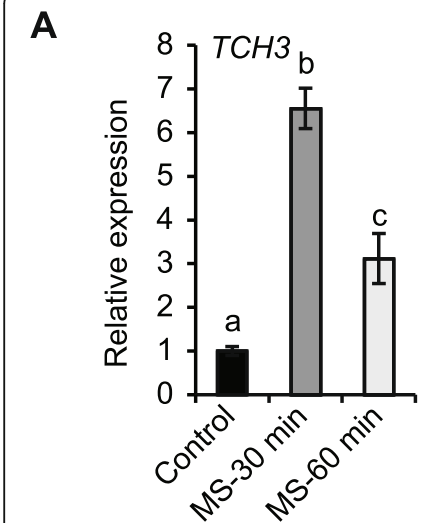

C

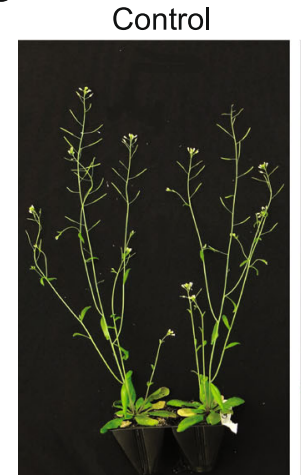

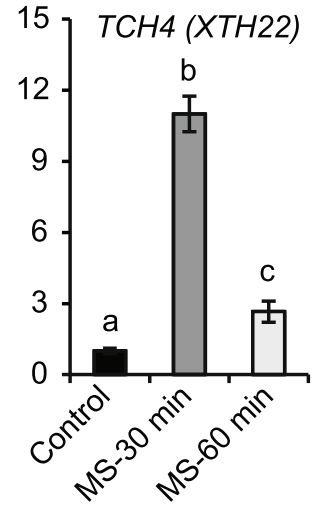

MS
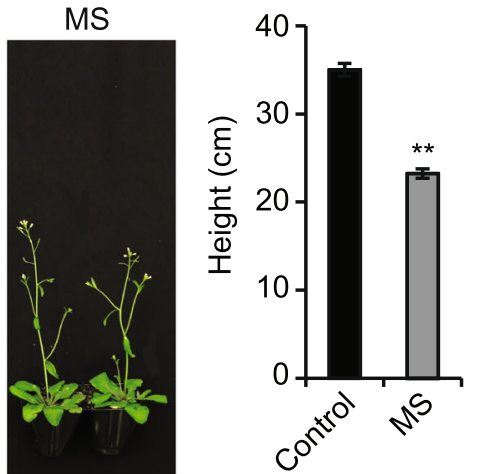

B

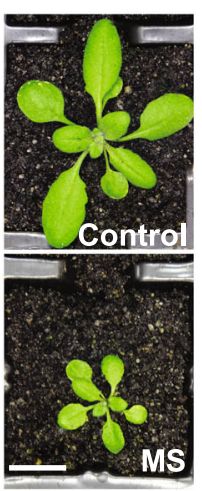

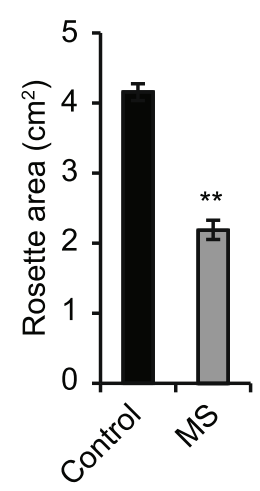

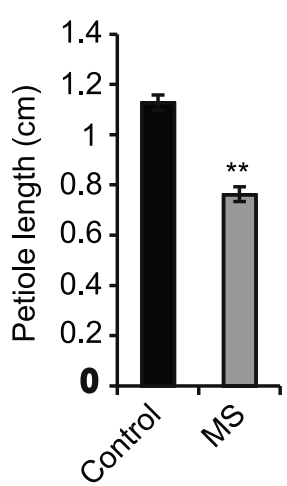

D

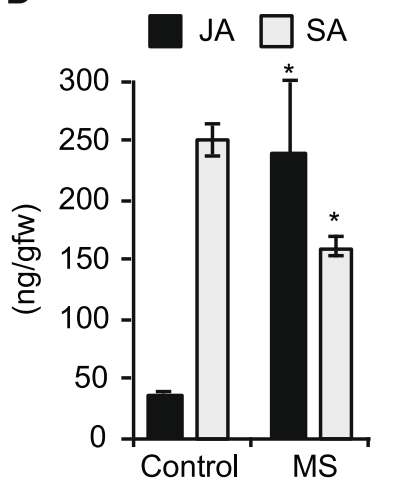

E

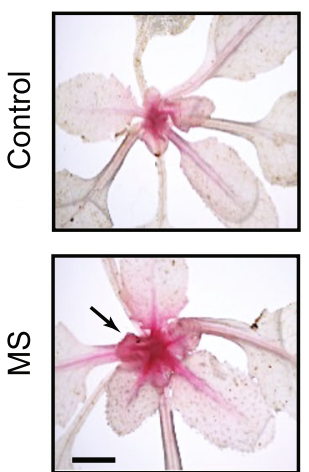

Fig. 1 Effect of a short period of MS to juvenile Arabidopsis seedlings. A TCH-inducible gene expression within 30 and 60 min after 10 s of MS. Relative mRNA expression levels were normalized using $\beta$-ACTIN as the housekeeping gene $(n=3)$. B Petiole length and rosette leaf area in a 10day old plant subject to 7-days of repetitive MS (touched twice daily for $10 \mathrm{~s}$ ). A representative image of a 17-day old plant has been displayed and data was averaged from scoring individual plants ( $n=15$ plants). C Floral stem height and reproductive architecture in MS-treated and control plants. 10-day old plants were subjected to 7-days of MS without any further stimulation and allowed to flower. Phenotypes were scored in a 35-day old plant from the main floral bolt. A representative image has been displayed and the floral stem height defines the average of multiple independent plants $(n=15)$. D Jasmonic acid $(J A)$ and salicylic acid (SA) levels were quantified in a whole rosette from juvenile plants subject to 7-days of MS. Leaves were harvested 30 min post-MS ( $n=10$ plants). E Leaves from controls and 7-days MS plants stained with phloroglucinol to highlight lignin accumulation as red colouration (indicated by arrow). Error bars show standard error of biological variation. Statistical significance denoted by letters $(\mathbf{A})$ was determined using ANOVA with the Bonferroni test, and asterisks (B, C, D) determined with student's t-test $(p<0.05)$. Scale bars $=B, 1 \mathrm{~cm} ; C, 5 \mathrm{~cm} ; \mathrm{E}, 1 \mathrm{~cm}$

71 gene (PRX71) which encodes cell wall-bound peroxidase that promotes lignification was significantly upregulated in MS-infected leaves compared to controlinfected leaves (Fig. 3B). This correlated with the enhanced lignin in MS plants compared to control plants (Fig. 1E). In addition, the transcript level of PHYTOALEXIN DEFICIENT 3 (PAD3) involved in phytoalexin (camalexin) biosynthesis, and defense against $A$. brassicicola [34] was significantly higher in MS-infected (8-fold) compared to control-infected (2.2-fold) plants (Fig. 3C). The increased lignin and callose deposition, as well as the hyper-induction of transcripts associated with camalexin, lignin and callose biosynthesis reveal that MS can enhance cell wall defenses to promote resistance against A. brassicicola.
MS increased ROS production as an early stress response to $A$. brassicicola infection in leaves- $(36 \mathrm{~h}$ postinoculation; hpi) (Fig. 3D). Five days post-inoculation, the expression of the ROS marker gene RESPIRATORY BURST OXIDASE HOMOLOGUE D (RBOHD; fine tunes the spatial control of reactive oxygen intermediates and hypersensitive response to the cell) [35] was significantly upregulated in control-infected plants (2.5-fold). However, $R B O H D$ expression was not altered in the MSinfected leaves resembling a control level response (1fold), despite the significant increase in the basal expression level of $R B O H D$ in MS-plants (3.0-fold) (Fig. 3D). The transcript levels of GLUTATHIONE S-TRANSF ERASE 1 (GST1; scavenges and detoxifies ROS) were significantly hyper-induced in MS-infected leaves (6-fold) 


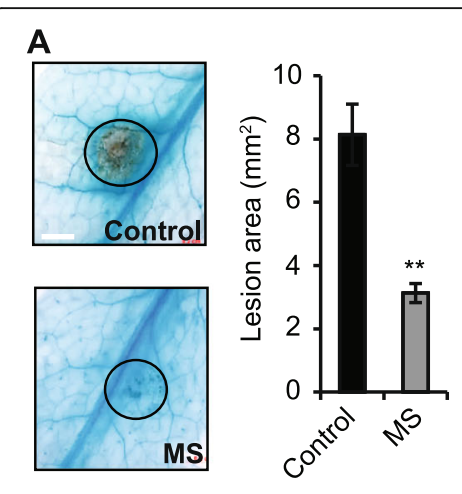

B
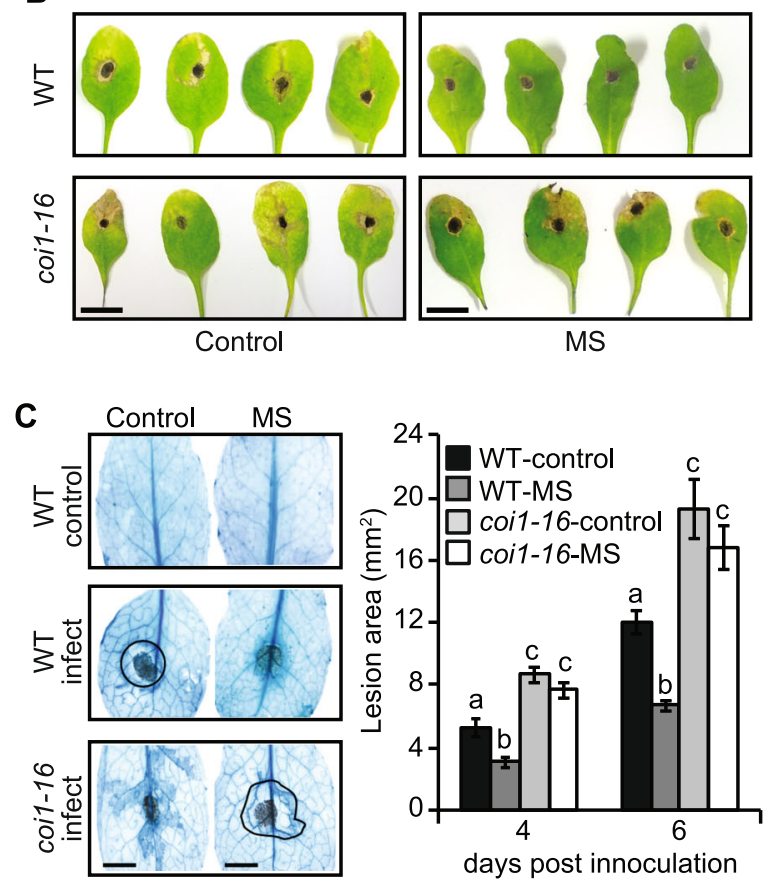

Fig. 2 Defense response of MS plants to $B$. cinerea and $A$. brassicicola infection. The 5 th to 7 th true leaf from 17-day old plants were inoculated with $5 \mu \mathrm{L}$ of $3.5 \times 10^{4}$ spores $/ \mathrm{mL}^{-1}$ of pathogens ( $n=15$ plants). A Lactophenol-trypan blue was used to stain fungal hyphae and to determine necrotic lesion denoted by circle in leaves from control and MS plants 48 hpi. A representative stained image and the average lesion area are displayed ( $n=15$ leaves). B

Representative images of leaves from MS wild-type plant (WT) and the JA mutant coil infected with A. brassicicola (5 dpi). C Necrotic lesions were stained with lactophenol trypan blue and the lesion area $\left(\mathrm{mm}^{2}\right)$ denoted by circle with arrow was measured to provide a quantitative measurement of pathogen proliferation $(n=15)$. All data are representative of at least two independent experiments. Error bars show the standard error of biological variation. Statistical significance denoted by letters was determined using ANOVA with the Bonferroni test $(P<0.05)$. Scale bars $=A, 0.2 \mathrm{~cm} \mathrm{~B}, 1 \mathrm{~cm} ; C, 0.3 \mathrm{~cm}$

compared to control-infected (3-fold) plants, but unaffected in control or MS plants (Fig. 3D). Therefore, prior exposure of plants to repetitive MS and subsequent infection with pathogens may enhance the scavenging and detoxification of ROS, which might otherwise facilitate the virulence of necrotrophic pathogens [36, 37].

JA mediates MS-induced resistance against $A$. brassicicola MS enhances JA accumulation (Fig. 1D), which can mediate resistance against insect attack and necrotrophic pathogen infection $[16,34,38]$. Therefore, we examined whether MS-induced resistance against A. brassicicola required JA signalling. The JA-insensitive signalling mutant, coi1-16, has been demonstrated to be insensitive to exogenous application of MeJA and impairs jasmonateinduced signalling and transcriptional regulation of plant defences $[18,39,40]$. Therefore we investigated if the insensitivity of coi1-16 to JA accumulation can likely impair the MS-induced resistance to A. brassicicola infection juxtaposed to the WT. Indeed, analysis of disease progression 5-days post-inoculation with A. brassicicola revealed that the coi1-16 mutant was highly susceptible to infection with or without MS compared to the WT (Fig. 2B). The coi1-16 plants showed enhanced leaf chlorosis and a larger necrotic lesion area (confirmed by staining with lactophenol trypan blue) surrounding the initial spore inoculation site when compared to WT (Fig. 2C). Therefore, a short period of MS to Arabidopsis seedlings can enhance defense against $A$. brassicicola infection via a JA-mediated signalling pathway.

\section{MS primes defense gene expression against $A$. brassicicola infection}

We tested whether MS plants subsequently challenged with $A$. brassicicola would show altered gene expression indicative of priming triggered by the short period of MS (Fig. 4). Genes analysed included; VEGETATIVE STORAGE PROTEIN 1 (VSP1; expression is induced by wounding and JA), OXOPHYTODIENOATE-REDUCTASE 3 (OPR3; encodes a protein required for jasmonate biosynthesis), ETHYLENE RESPONSE FACTOR 2 (ERF2; induced by JA and ethylene), PLANT DEFENSIN 1.2 (PDF1.2; encodes an ethylene- and jasmonate-responsive plant defensin protein), as well as PHYTOALEXIN DEFI CIENT 3 (PAD3) and PATHOGENESIS-RELATED GENE 1 (PR1; a marker gene induced by SA and indicative of a systemic acquired response). Five days postinoculation, leaves from the control-infected plants showed enhanced expression of VSP1 (17.5-fold), OPR3 (3.8-fold), ERF2 (2.1-fold), PAD3 (2.1-fold), PDF1.2 (232.2-fold) and PR1 (1.8-fold) relative to those from control-uninfected plants (Fig. 4A). In MS-treated plants, the basal expression level of OPR3, ERF2 and $P A D 3$ remained unchanged. Interestingly, the basal level of expression of VSP1, PDF1.2, and PR1 remained constitutively higher (4.1-, 35.6-, and 2.1-fold, respectively) up to 5-days post-MS. MS-infected plants showed a 


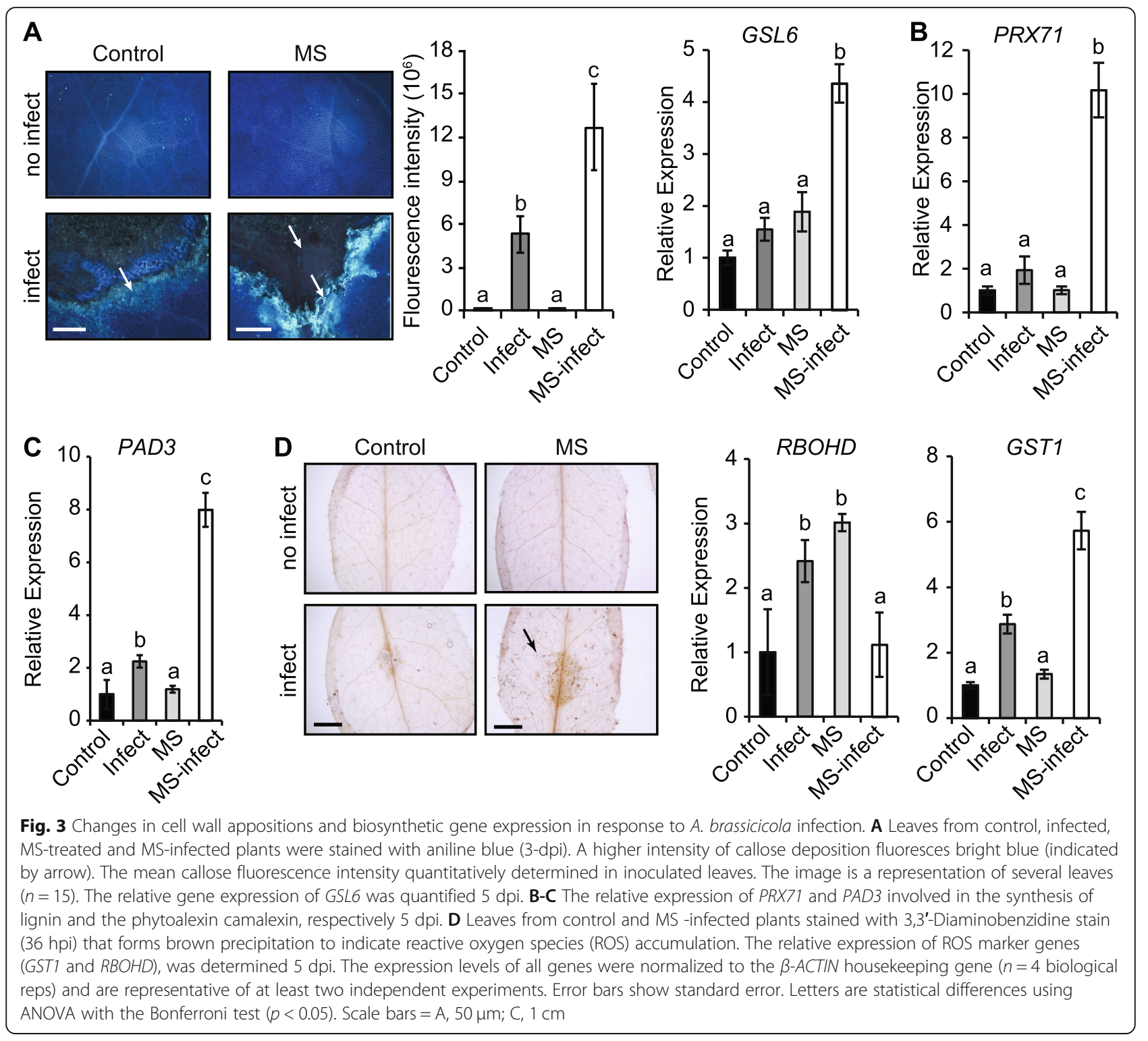

significant hyper-induction of VSP1 (40-fold), OPR3 (9.1-fold), ERF2 (3.4-fold) and PAD3 (8-fold) compared control-infected plants (Fig. 4A). In contrast, PDF1.2 and PR1 expression was negatively regulated in MSinfected relative to control-infected tissues. That is; PDF1.2 expression was reduced from 232.2 (control-infected) to 76.1-fold (MS-infected), while PR1 expression was not significantly different to that of control plants (Fig. 4A). The hyper-induction or negative regulation of gene expression in MS-infected WT plants evidences that MS can prime a differential gene expression in response to subsequent pathogen infection.

We reasoned that a JA-mediated signalling pathway might facilitate the MS-induced priming of gene expression. The transcript levels of VSP1, OPR3, ERF2, PAD3,
PDF1.2, and PR1 were quantified in leaves from coil-16 plants compared to WT after $5 \mathrm{dpi}$ when we observed more significant differences in pathogen infection (Fig. $2 \mathrm{~B}$ and $\mathrm{C})$. The basal expression level of VSP1 (0.5-fold) and PDF1.2 (0.01-fold) were reduced in control coil-16 (Fig. 4B) compared to WT plants (Fig. 4A). The expression of VSP1 (2.7-fold), OPR3 (2.2-fold), ERF2 (2.5-fold) and PR1 (3.9-fold) were upregulated in coil-16 infected tissues. Contrasting gene expression patterns between WT and coi1-16 infected tissues revealed that PDF1.2 and PAD3 expression were no longer induced in coil16-infected tissues. The induction of VSP1 expression was reduced (17.5- to 2.7 -fold), while the induction of PR1 expression was slightly higher (1.8- to 3.9-fold) in coi1-16 compared to the WT (compared Fig. 4A to B). 


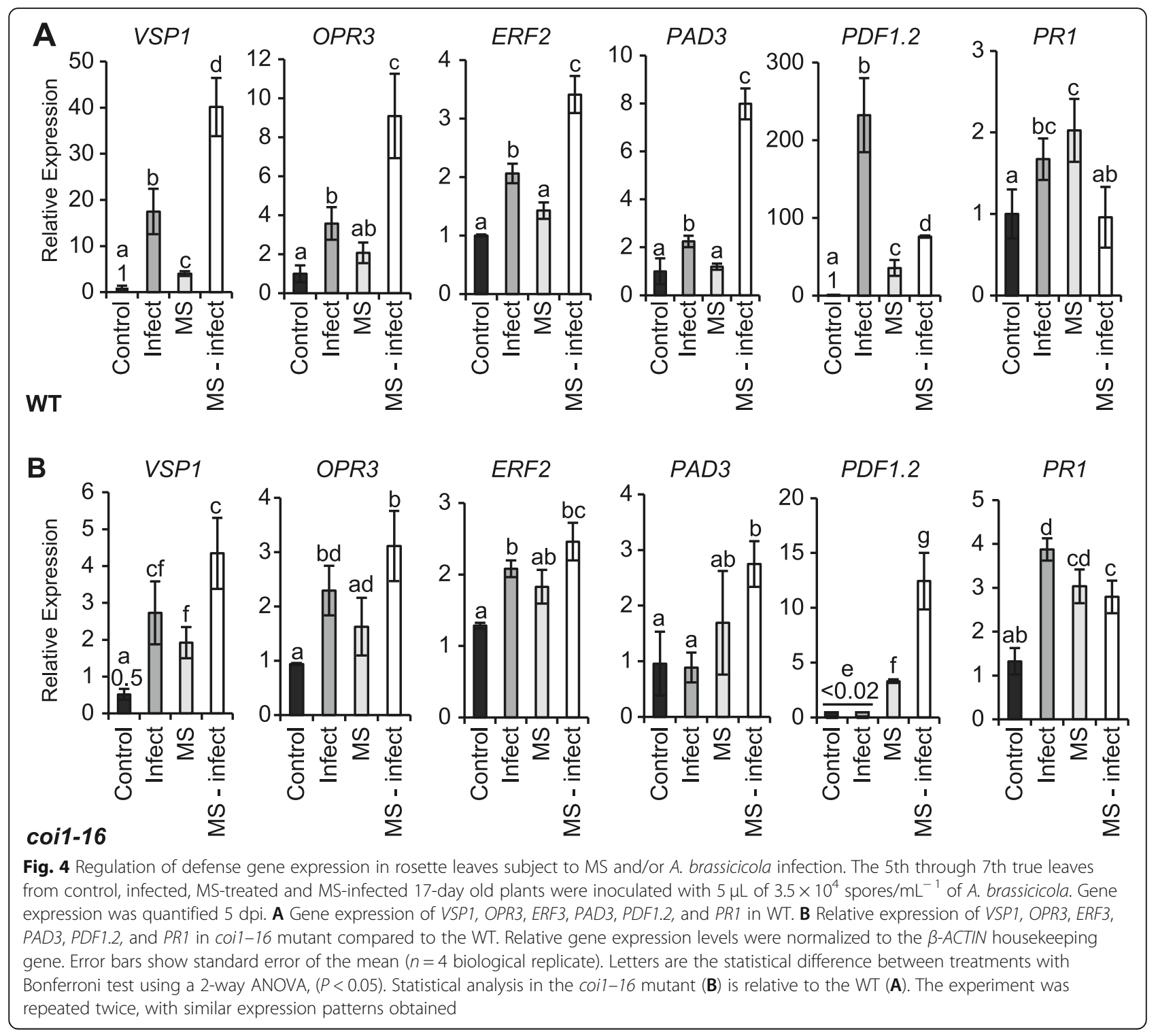

Interestingly, 5-days after ceasing MS, coi1-16 MS plants showed an increase in the basal level of expression of VSP1 (2-fold) and PDF1.2 (3.3-fold) although significantly less compared to the WT except PR1 (3-fold) which showed similar expression to the MS-treated WT plants (compare Fig. 4B and A). The hyper-induction of some gene expressions (e.g. VSP1, OPR3, and ERF2) observed in MS-infected tissues of WT (Fig. 4A), was not evident in MS-infected tissues of coil-16 (Fig. 4B). The induction of PAD3 (2.7-fold) and PDF1.2 (13.5-fold) was apparent in coi1-16 MS-infected plants albeit significantly lower ( $>2.5$-fold less) compared to MS-infected WT plants (compare Fig. 4A and B). The MS actually caused the hyper-induction of PDF1.2 expression in coil-16 infected plants (15-fold), a contra-regulation to reduction that was observed in MS-infected WT plants (compare Fig. 4A and B). Similarly, the induction of PR1 expression in MS-infected coi1-16 plants (2.8-fold) was reduced in MS-infected WT plants (0.9-fold) (compare Fig. 4A and B). Therefore, JA signalling mediated by COI1 appears to prime the hyper-induction and/or contra-regulation of gene expression in MS-treated plants upon challenge with $A$. brassicicola.

\section{MS altered defense gene expression in naïve cauline leaves}

The reduction in floral stem height observed in MStreated plants several days post-stimulation (Fig. 1B), prompted us to test if naive cauline leaves that differentiate from the inflorescence stem would also show an 
altered defense response to $A$. brassicicola infection. Gene expression analysis at 2 dpi showed significant upregulation of VSP1 (3-fold), OPR3 (2.3-fold), ERF2 (2.7fold), PDF1.2 (337.1-fold) and PR1 (49.2-fold) expression in control-infected cauline leaves (Fig. 5A-B), a trend

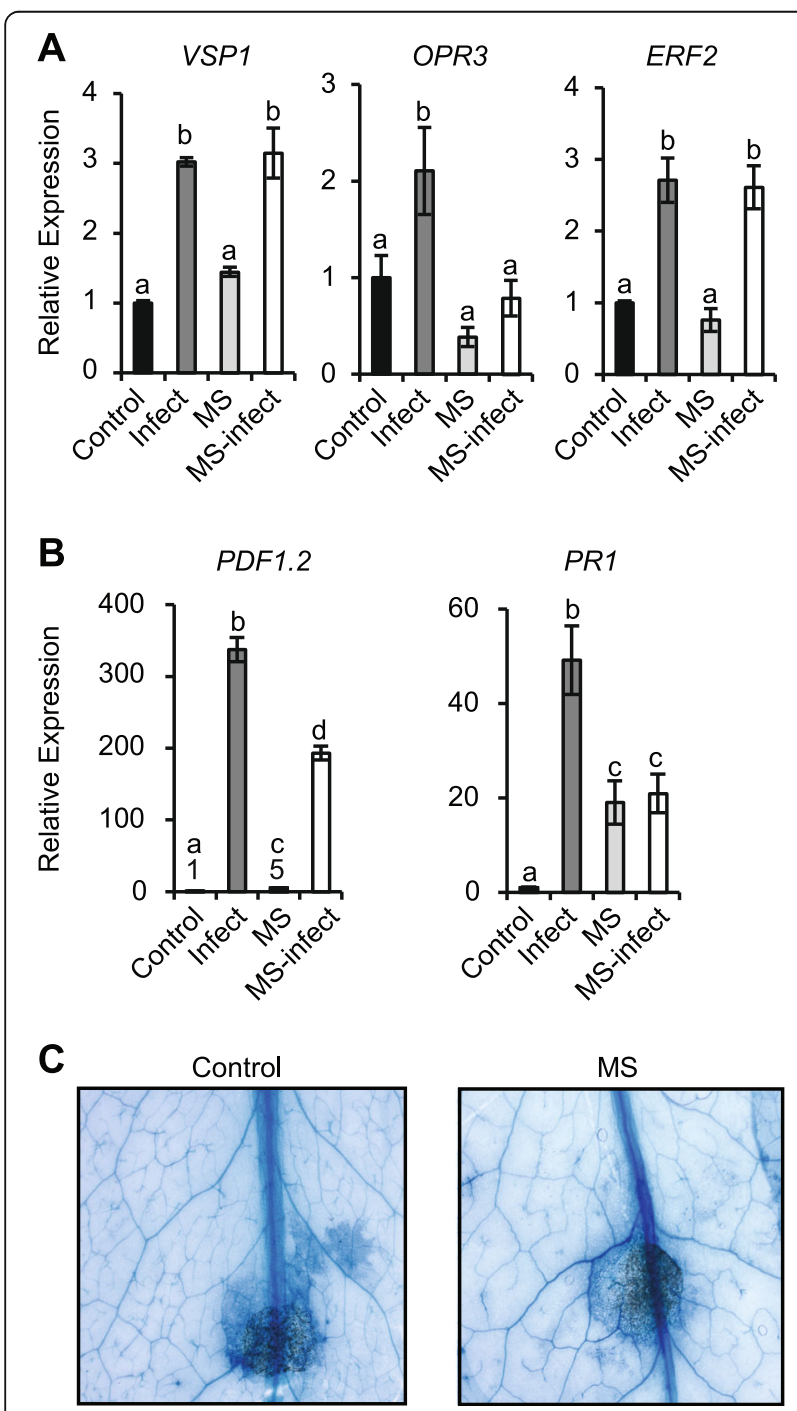

Fig. 5 Analysis of defense gene expression and disease symptoms in naïve cauline leaves challenged with A. brassicicola. Ten days old WT plants MS for 7-days was allowed to grow without further stimulation until 2-3 cauline leaves emerged from the primary floral stem. The 1st and/or 2nd cauline leaves from MS-treated and control plants were inoculated with $5 \mu \mathrm{L}$ of $3.5 \times 10^{4}$ spores $/ \mathrm{mL}^{-1}$ of A. brassicicola. A, B The relative expression of pathogen-related defense genes in cauline leaves from control, and MS plants, 2 dpi. C Three days post-inoculation, cauline leaves were stained with lactophenol trypan blue to reveal the necrotic lesion area. Representative cauline leaves are displayed from two experiments showing similar results. Gene expression levels were normalized to the $\beta$-ACTIN housekeeping gene. Error bars show the standard error of the mean $(n=4)$. Letters are statistical differences between treatments with Bonferroni test using ANOVA, $P<0.05$. The experiment was performed twice with similar results similar to that observed in control-infected rosette leaves (Fig. 4A). The expressions of VSP1, OPR3 and ERF2 were similar in the cauline leaves from MS and control plants (Fig. 5A). Interestingly, the basal level of expression of PDF1.2 (5.0-fold) and PR1 (19.1-fold) was constitutively upregulated in cauline leaves from MS plants (Fig. 5A), a trend also observed in rosette leaves (Fig. 4A). The expression of VSP1 and ERF2 was similar in infected cauline leaves from control and MS plants (Fig. $5 \mathrm{~A})$, revealing that the hyper-induction observed in MSinfected rosette leaves (Fig. 4A) was not retained in naïve cauline leaves. In contrast, PDF1.2 and PR1 expressions were negatively regulated in infected cauline leaves from MS-treated versus control plants (Fig. 5B), a trend also observed in infected rosette leaves (Fig. 4A). Analysis of cell death by staining with lactophenol trypan blue did not reveal any significant difference in disease susceptibility in cauline leaves from MS and control plants (Fig. $5 \mathrm{C})$. Although the pre-exposure of the juvenile seedlings to MS was not sufficient to prime resistance in cauline leaves against $A$. brassicicola infection, the short period of MS could alter defense gene expression in naive cauline tissues.

\section{Discussion}

The application of MS twice daily to juvenile Arabidopsis plants for 7-days can enhance JA accumulation and facilitate thigmomorphogenesis. MS provided plants with an advantage to respond stronger or faster to subsequent challenge with $B$. cinerea and $A$. brassicicola infection by priming the hyper-induction and/or contraregulation of gene expression associated with disease resistance. Here we discuss how MS induced defensive barriers and heightened JA signalling responses that trigger resistance against the infection by multiple necrotrophic pathogens and long lasting changes in gene expression indicative of the maintenance of epigenetic memory (Fig. 6).

\section{MS triggers defensive barriers to limit necrotrophic pathogen infection}

MS-induced alterations in cell wall components can compensate for structural integrity challenges and contribute to plants first line of defense against pathogens [41-43]. For instance, MS enhanced the accumulation of callose, a $(1,3)-\beta$-glucan polymer that reinforces cell wall at $A$. brassicicola penetration site to limit infection (Fig. 3) [44]. This is consistent with a report showing callose accumulation in MS-strawberry leaf tissues challenged with B. cinerea [6]. Callose deposition correlated with the hyper-induction of GSL6 gene expression in MSinfected leaves. Reports show that the overexpression of Arabidopsis GSL5 promoted resistance during the early stage of powdery mildew infection in Arabidopsis [45, 


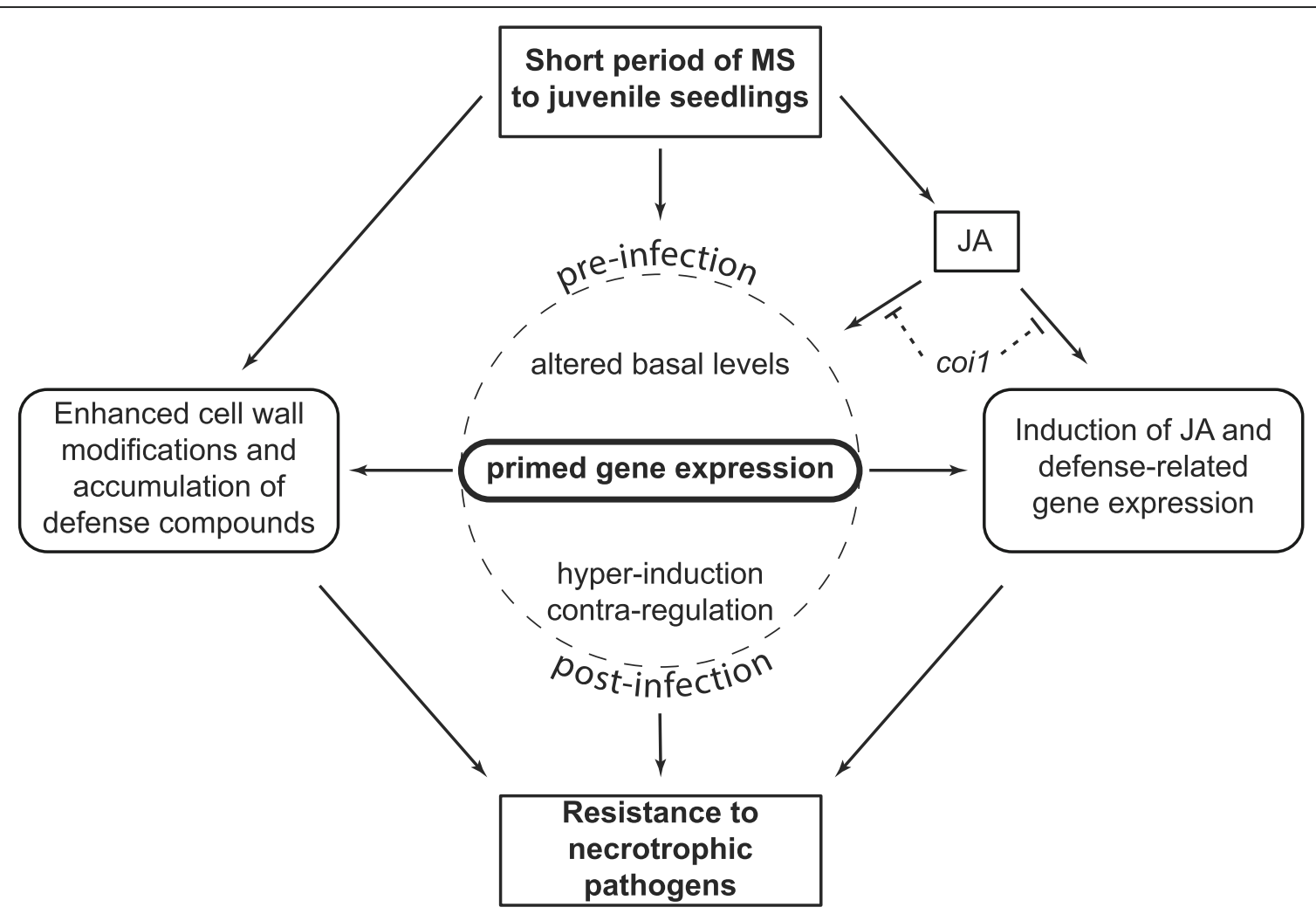

Fig. 6 A model showing how prior exposure of juvenile seedlings to a short period of MS can prime gene expression and resistance to subsequent necrotrophic pathogen infection. The first stress encounter induced by repetitive MS (pre-infection) causes: 1) an increase in JA accumulation, 2) the accumulation of defense compounds (e.g. lignin and callose) that promote structural barriers, and 3) altered levels of basal gene expression. The secondary stress encountered by inoculating MS-treated plants with A. brassicicola causes the hyper-induction or contraregulation of gene expression five-days post-infection that primes resistance to necrotrophic pathogen infection. A genetic perturbation in JA signalling mediated by the coronatine-insensitive 1 (coi1-16) mutant affected the priming of gene expression and rendered MS-treated plants susceptible to infection

46], and silencing of barley HvGSL6 gene expression increased disease susceptibility to Blumeria graminis f.sp. hordei in barely [47]. Thus, the hyper-induction of GSL6 expression and enhanced callose deposition in MSinfected tissues could limit pathogen penetration.

Lignin and camalexin are other cell wall structural compounds associated with promoting plant defence against pathogens. The PRX71 gene encodes a cell wallbound PEROXIDASE protein that functions to reduce cell expansion and cell wall damage, thereby limiting intracellular spaces for pathogen entry [48]. The overexpression of PRX71 triggers lignification in Arabidopsis and increases resistance against B. cinerea [48-50]. Indeed, MS-treated leaves enhanced lignin deposition, and upon infection caused the hyper-induction of $P R X 71$ expression (Figs. 1 and 3). The PAD3 gene encodes a cytochrome P450 enzyme that catalyses the conversion of dihydrocamalexic acid to camalexin, a compound that promotes resistance against pathogens [51, 52]. The loss-of-function mutation in PAD3 enhances susceptibility to A. brassicicola in Arabidopsis [34], revealing that the hyper-induction of PAD3 in MS plants could contribute to MS-induced resistance against $A$. brassicicola (Fig. 3). Therefore, the enhanced JA accumulation (Fig. 1D) and PAD3 expression could synergistically contribute to disease resistance as previously reported [34, 53]. The oxidative stress-related gene GLUTATHIONE S-TRANSFERASE 1 (GST1), which encodes for a protein that can catalyse the synthesis of glutathione-indole-3-acetonitrile, a precursor of camalexin biosynthesis [54] was also hyper-induced in MSinfected tissues (Fig. 3). Prior exposure of plants to MS and subsequent infection culminated in the hyperinduction of PRX71, PAD3 and GST1 expression, whose protein encoded products contribute to the biosynthesis of chemical compounds that promote resistance against A. brassicicola infection.

ROS accumulated in MS-treated leaf tissues subject to A. brassicicola infection (36 hpi of MS plants) (Fig. 3), consistent with previous reports in MS-treated 
strawberry and Arabidopsis leaves subjected to B. cinerea infection $[6,8]$. ROS may facilitate the early signal transduction of MS responses, but may not be directly involved in MS-induced resistance. The loss-of-function in $R B O H D$ and $R B O H F$ genes were shown to impair ROS production [55], but were not involved in MS-induced defense against $B$. cinerea infection since MS-treated rbohd and rbohf mutants displayed a WT-like resistance to infection [8]. This reveals that the MS-induced resistance may be independent of ROS signalling. Exposure of plants to MS constitutively upregulated $R B O H D$ expression up to 5-days post-stimulation. However, upon infection $R B O H D$ expression in MS-treated plants was negatively regulated back to basal levels of expression, similar to the control (2.6-fold less) (Fig. 3). The reduced $R B O H D$ expression in MS-infected plants could be due to the hyper-induction of GST1 and PRX71 expression, whose products are involved in ROS scavenging and hydrogen peroxide catabolic processes [56]. Thus, MS prior exposure of plants to repetitive MS may signal ROS limiting processes upon subsequent challenge with A. brassicicola to reduce cell death that could otherwise facilitate the virulence of necrotrophic pathogens [36, 37].

\section{JA signalling mediates MS-induced resistance against necrotrophic pathogen infection}

A single event of soft MS by rubbing Arabidopsis leaves between the thumb and forefinger showed that JA may not be required for MS to mediate resistance against $B$. cinerea infection [8]. This is in contrast to a previous report that linked 4-weeks of MS-induced JA accumulation to B. cinerea resistance in Arabidopsis [16]. There could be differences in the acclimation response triggered by single versus prolonged MS. For example, a single event of MS [16] may transiently induce JA responses [9] that are not sufficient to induce thigmomorphogenesis [9] and elicit long-term JA-mediated responses. While, repetitive MS for days as shown here can enhance JA levels that culminate in growth changes in the plant and a long-lasting defense response $[9,16]$. Here, we demonstrate that a short 7-day period of MS (twice daily during each photoperiod, for $10 \mathrm{~s}$ with an 8 $\mathrm{h}$ interval) with a soft brush can trigger thigmomorphogenesis, increase JA levels and promote resistance against $A$. brassicicola infection (Fig. 1).

JA is required to signal defense against necrotrophic pathogen infection [57]. For example, a prolonged period of MS shown to induce resistance in Arabidopsis to B. cinerea infection was impaired in the opr 3 mutant, and enhanced by the constitutive overexpression of OPR3 [16]. Our result confirmed that the loss-of-function in COI1, an F-box protein essential for jasmonate responses and transcriptional regulation [18], compromised the MS-induced resistance to A. brassicicola infection (Fig. 2). The coi1-16 mutant affected cell wall remodelling in Arabidopsis [58] and has a secondary mutation in PENETRATION 2 (PEN2; implicated in resistance to pathogenic fungi) that can restrict pathogen growth in the cell periphery [59]. Thus, impairment in coi1-16 may not only affect MS-induced JA resistance, but also the accumulation of cell wall components that impair the invagination of fungal hyphae within intracellular spaces [60]. We conclude that JA signalling via COI1 mediates the MS-induced resistance against necrotrophic pathogen infection (Fig. 6).

A. brassicicola infection activated JA defense gene expression, keeping consistent with previous reports [29, 34]. An Arabidopsis genechip array showed that $12-36 \mathrm{~h}$ post-inoculation, before the onset of disease symptoms, many $A$. brassicicola induced genes were strongly increased in the WT plants compared to coil-16 plants. VSP1 and PDF1.2 were significantly reduced in coil mutant, while OPR3 involved in JA biosynthesis was found to be independent of coil at the later stages of infection, keeping consistent with our data (compare Fig. 4) [34]. The regulation of gene expression in MS-treated plants at 5-dpi inoculation when there were visible differences in disease susceptibility was contrastingly different between WT and the coil-16 mutant. The hyper-induction of VSP1, OPR3, ERF2 and PAD3 expression and/or contra-regulation of $P D F 1.2$ and $P R 1$ expression was either abolished or less evident in coi1-16 compared to WT (Fig. 4). Consistent with a previous report [34], PR1 was enhanced in coil mutant indicating antagonistic effect of JA on PR1 signalling via COI1 pathway. The reduction of PDF1.2 in the WT MS-infected rosette and cauline leaves compared to the WT control-infected plants revealed that MS negatively regulated PDF1.2 expression upon pathogen infection via unknown mechanisms. A report indicates that GLUTAREDOXIN 480 interaction with TGA factors can impair the expression of PDF1.2 [61], but it is unknown if such mechanism occurs in response to MS. The basal expression level of VSP1 and PDF1.2 in coi1-16 mutant was constitutively reduced $(>50 \%)$ indicating that JA signalling via COI1 is required to enable their expression and responses to MS. We conclude that JA signalling mediated through COI1 facilitates the hyper-induction and/or altered regulation of gene expression in MS-infected plants (Fig. 6).

\section{MS primes defense responses upon subsequent pathogen infection}

Previous exposure of juvenile Arabidopsis seedlings to a short period of MS enhanced the molecular response in adult plants to subsequent infection by $A$. brassicicola revealing that MS can prime defense against pathogens. MS-infected plants accumulated cell wall compounds 
that provided stronger defense barrier against pathogen invasion. Subsequent challenge of MS plants with $A$. brassicicola culminated in the hyper-induced expression of defense genes (VSP1, OPR3, ERF2, PAD3, PRX71, GSL6 and GST1) by approximately 2 -fold, revealing that prior exposure of juvenile plants to MS can mount a stronger defense response and hence resistance to $A$. brassicicola infection. The response persisted in adult rosette leaves lasting for up to 4-5 days after MS had ceased, evident by the hyper-induction of defense gene expression. However, the primed defense response did not persist throughout the plants' life cycle, since cauline leaves that emerged from MS-treated plants showed a WT-like susceptibility to infection (Fig. 5). The hyperinduction of VSP1, OPR3 and ERF2 gene expression was not observed in cauline leaves, yet the contra-regulation of PDF1.2 and PR1 gene expression apparent in rosette leaves was still evident in cauline leaves from MS plants, perhaps reflecting a stress-induced memory. Therefore, the short-term MS-induced resistance in rosette leaves was erased in naive cauline leaves in the absence of continued repetitive MS. The resetting of MS-induced memory would limit the energy cost associated in maintaining long-term immunity that might otherwise negatively affect growth and reproduction [24, 62].

Priming occurs at a physiological (hormonal changes), molecular (gene regulation), and/or epigenetic levels (DNA or histone modifications), essentially providing an acclimation strategy to heighten the plant's defense capacity against future attack [24]. Prolonged drought, cold, salinity, light and pathogen infection have been reported to prime gene expression and strengthen the plant's response to future stress encounters [21, 63-65]. We attribute the hyper-induction or contra-regulation of gene expression in MS plants to the higher endogenous JA levels, since the coi1-16 JA signalling mutant impaired this heightened response (Fig. 6) [62].

\section{MS causes long-lasting changes in gene expression}

MS is a ubiquitous stress stimulus perceivable by plants during development. Unstressed and naïve plants were proposed to maintain 'memory' of repetitive MS to prevent unwanted thigmomorphogenesis [14, 15, 66]. Our data demonstrates that pre-exposure of a plant to a short period of MS can constitutively upregulate the basal level of RBOHD, VSP1, PDF1.2 and PR1 expression for up to 5 days post-stimulation (Fig. 4). The upregulation of PDF1.2 and PR1 remained evident in naive cauline leaves that had not yet developed when MS was ceased > 10 days early before any sign of floral stem emergence from the adult rosette. Cells within the shoot apical meristem of juvenile seedlings remain in an undifferentiated state until the plant transitions from vegetative to reproductive stage, where the inflorescence meristem develops around 14 days after germination [67]. Thus, the altered level of gene expression in cauline leaves reveal that a short period of MS may have created a 'stress memory' in the shoot meristem of juvenile plants that was mitotically inherited through cell division into the inflorescence meristem [24-26]. The cauline tissues would have differentiated from specialised cell types within the inflorescence meristem during reproductive development and have retained some memory evident by the constitutively higher basal expression level of some genes. Future work on whether MS induced resistance in leaves can systemically be transferred to the root, a critical organ exposed to pathogens, symbionts and mechanical stress as it navigates through the soil will help us further understand the overall effect of MS on plant immunity.

Juvenile seedlings have the plasticity to respond to stress in their growing environmental; such as when a prolonged period of cold exposure (e.g. vernalization) triggers the early flowering of adult Arabidopsis plants mediated by histone modifications [68]. Stress-induced memory can persist in plants via epigenetic processes (histone modifications or DNA methylation) to alter a plants' response to future encounters and in some cases can be inherited $[21,65]$. For instance, the chromatin-modifying enzyme, SET DOMAIN GROUP 8 (SDG8), promotes permissive histone lysine methylation surrounding $\mathrm{TOUCH}$, pathogen and flowering-time responsive genes and plays a key role in promoting vernalization as well as thigmomorphogenesis [22, 69, 70]. Further investigation is required to elucidate the mechanisms by which a short period of MS to 10 days old juvenile seedling can alter the basal levels and/or contra-regulate gene expression in rosette and naïve cauline leaves.

\section{Conclusions}

Mechanical stress has been used in farming for a longtime to harden crops and promote stress acclimation [1, 16]. The mechanism by which MS can promote stress tolerance and defense responses is not well understood. Genome-wide transcriptome analysis shows that a short period of MS can enhance the expression of several genes implicated in stress responses $[9,10,12,71]$. Here, we showed that a short period of repetitive MS to juvenile seedlings promoted resistance and primed defense gene expression upon subsequent challenge with pathogens via JA signalling. Prior exposure of plants to MS altered cell wall appositions and defense-related metabolites that can be attributed to the enhanced resistance against $A$. brassicicola. The altered gene expression in cauline leaves in the absence of further MS supported previous reports implicating epigenetic processes in facilitating thigmomorphogenesis [21, 24, 65]. 
Understanding the factors (the duration, intensity, the age of the plant as well as signalling pathways and genome-wide regulation) that enable MS acclimation responses in plants could help growers to utilise MS to induce defense mechanisms in greenhouse propagated seedlings before transplanting them into the field.

\section{Methods}

\section{Plant materials and growth conditions}

The JA-insensitive mutant coi1-16 (CS68788) was obtained from TAIR and coi1-21 (SALK_035548) was obtained from Prof. Jose Ramon Botella (University of Queensland, Australia) [72]. Both coil alleles have a Col0 wild-type background and were supplied as homozygous seed stock lines with the same gene locus (AT2G39940). coil mutant alleles have a characteristic male sterile phenotype and will not set seeds when grown at normal growth temperatures [73]. However, when coil mutant alleles are grown at $16^{\circ} \mathrm{C}$ male fertility is restored and seeds set normally as previously described [74]. We assessed the phenotypes of coil-16 in comparison to coil-21, confirming that all siblings from both germplasms displayed a male sterile phenotype and displayed no notable differences in growth or morphology. However, when these alleles were grown in the cold, we got more seeds from coil-16 and hence selected this germplasm for subsequent studies described in this paper. There were no other obvious differences in phenotypes of the two coil alleles when grown in the cold (data not shown).

Seeds were grown in sterilized seed raising mixture soil (DEBCO Pty, Australia) with slow-release fertilizer (Osmocote, Garden City Plastics, Australia) and stratified at $4{ }^{\circ} \mathrm{C}$ for $2-3$ days before being transferred to the growth chamber at $22{ }^{\circ} \mathrm{C}$ with $16 \mathrm{~h}$-light $/ 8 \mathrm{~h}$-dark photoperiods with a relative humidity of $60 \%$ and a light intensity between 140 and $150 \mu \mathrm{mol} \mathrm{m}^{-2} \mathrm{~s}^{-1}$. Plants were watered from the bottom of growth trays once every week.

\section{Mechanical stimulation of plants}

Juvenile plants (10-12 days old after growth, DAG) were gently stimulated by touching the rosettes clockwise and anticlockwise for $8-10 \mathrm{~s}$ with a very soft brush to constitute a single MS. Care was taken not to break the leaves as this could result in a wound-induced response. For repetitive mechanical stress, touch was done twice daily (with $8 \mathrm{~h}$ intervals) for 7-days (MS) unless otherwise stated. After 7-days of mechanical stimulation, images of both touch and untouched plants were taken for analysis of thigmomorphogenetic traits (rosette area, petiole length, and inflorescence height) with ImageJ software (https://imagej.nih.gov/ij/download.html). The plant height measured corresponds to the main floral bolt.

\section{Pathogen assays}

Pathogen culture and plant infection were performed as previously described [72, 75]. Pathogens used for the experiment were A. brassicicola (isolate DAR 27028) and Botrytis cinerea (DAR 77536) both were obtained from the Department of Primary Industries, NSW (http:// www.dpi.nsw.gov.au). The pathogens were grown on potato dextrose agar (PDA) plate for about 12-14 days at $23^{\circ} \mathrm{C}$. The B. cineria and A. brassicicola matured spores showed visible black and brown colouration respectively on PDA plate. Spores were washed from the plate with distilled water, filtered with miracloth and counted with a haemocytomer. Test plants were covered with a transparent plastic dome to increase humidity the day before inoculation as previously described [34]. Plants were drop-inoculated with $5 \mu \mathrm{l}$ of $3.5 \times 10^{4}$ spores $/ \mathrm{mL}$ of $B$. cinerea or $A$. brassicicola and disease symptoms scored for necrotic spots and chlorosis. Disease progression was analysed by taking images of leaves and the necrotic lesion area was measured with Image J software (https://imagej.nih.gov/ij/download.html).

\section{RNA extraction, cDNA synthesis, and gene expression analyses}

Leaf tissues were collected at indicated time point and quickly frozen in liquid nitrogen. Samples were grounded with TissueLyser (Qiagen) in a $2 \mathrm{~mL}$ Eppendorf tube containing two steel balls. RNA for gene expression analysis was extracted using Spectrum Plant Total RNA Kit (Sigma) following the manufacturers' protocol. First-strand cDNA was made using Transcriptor First Strand cDNA Synthesis Kit (Roche). Quantitative RT-PCR was performed using a Roche Light Cycler 480 (http://www.roche.com) with FastStart DNA Master SYBR Green I kit (Roche) as described in the manual. Primers were designed across exon junction using the online Primer3Plus program (http://www.bioinformatics. nl/cgi-bin/primer3plus/primer3plus.cgi). Secondary structures were identified to eliminate primer-dimers using the IDT UNAFOLD program (https://sg.idtdna.com/UNAFold). Gene expression levels relative to the previously validated reference gene $\beta$-ACTIN2 (At3g18780) were used for each cDNA sample following the Pfaffle method [76]. Only $A C T 2$ was used because it did not change its transcription in response to MS in our experimental setup. Specific primer sequences for analysis are listed in Table 1 . Primer quality and efficiency were checked by creating serial dilution and a standard curve for each primer to correctly determine amplification efficiency and to remove bad primers. Primers had an efficiency range between 90 and $100 \%$. 
Table 1 List of qPCR primers

\begin{tabular}{|c|c|c|c|c|}
\hline Primer name & Function & & Primer sequence $\left(5^{\prime}-3^{\prime}\right)$ & Locus \\
\hline \multirow[t]{2}{*}{$\overline{P R 1}$} & Induced by SA & $\mathrm{F}$ & TGCAGTGGGACGAGAGGGT & AT2G14610 \\
\hline & & $\mathrm{R}$ & CCACATGTTCACGGCGGAGA & \\
\hline \multirow[t]{2}{*}{$\mathrm{RBOHD}$} & Response to ROS & $\mathrm{F}$ & GGTTCAACGCCTITTGGTA & AT5G47910 \\
\hline & & $\mathrm{R}$ & CGGTTTGATGCTTGATCTGA & \\
\hline \multirow[t]{2}{*}{ PDF1.2 } & $\mathrm{ET} / \mathrm{JA}$ response & $\mathrm{F}$ & GTTGCATGATCCATGTTTGG & At5g 44420 \\
\hline & & $\mathrm{R}$ & САCCCTTATCTTCGCTGCTC & \\
\hline \multirow[t]{2}{*}{ ACTIN 2} & Reference gene & $\mathrm{F}$ & TGTCGCCATCCAAGCTGTTCTCTCC & AT3G18780 \\
\hline & & $\mathrm{R}$ & ACGTCCAGCAAGGTCAAGACGGAGG & \\
\hline \multirow[t]{2}{*}{ GSL6 } & Callose deposition & $\mathrm{F}$ & CAAACCATGACGCTCCATAA & AT1G05570 \\
\hline & & $\mathrm{R}$ & GGTTCGTGGTATCACCCTTG & \\
\hline \multirow[t]{2}{*}{ PRX71 } & Stem lignification & $\mathrm{F}$ & TTGTTGAACGGCAACGGAGTCACG & AT5G64120 \\
\hline & & $\mathrm{R}$ & AGCCGCTCGTGACACAGTCATTCT & \\
\hline \multirow[t]{2}{*}{ OPR3 } & JA pathway & $\mathrm{F}$ & ACGTGGGAACCATCGGGCAACAAA & At2g06050 \\
\hline & & $\mathrm{R}$ & AGCAAGTTGTGGAAGCAGTTCACGC & \\
\hline \multirow[t]{2}{*}{ VSP1 } & JA signalling & $\mathrm{F}$ & GGATCGAAGTTGACGCAAGTG & AT5G24780 \\
\hline & & $\mathrm{R}$ & CTCAACCAAATCAGCCCATTG & \\
\hline \multirow[t]{2}{*}{ PAD3 } & Camalexin biosynthesis & $\mathrm{F}$ & TTCCTCTGTTTCCTCGTCCT & AT3G26830 \\
\hline & & $\mathrm{R}$ & ATGATGGGAAGCTTCTTTGG & \\
\hline \multirow[t]{2}{*}{ GST1 } & Glutathione binding & $\mathrm{F}$ & TAATAAAAGTGGCGATGACC & AT1G02930 \\
\hline & & $\mathrm{R}$ & ACATTCAAATCAAACACTCG & \\
\hline \multirow[t]{2}{*}{$\mathrm{TCH} 3$} & Calcium signalling & $\mathrm{F}$ & AGCCTTCCGCGTATTCGACAAGA & AT2G41100 \\
\hline & & $\mathrm{R}$ & CCGTCACCATCTGCATCCGC & \\
\hline \multirow[t]{2}{*}{$\mathrm{TCH} 4(\mathrm{XTH} 22)$} & Cell wall modification & $\mathrm{F}$ & TGTCTCCTITGCCTTGTGTG & AT5G57560 \\
\hline & & $\mathrm{R}$ & GAAACTCCGCAGGAACAGTC & \\
\hline \multirow[t]{2}{*}{ ERF2 } & Response to ET & $\mathrm{F}$ & TGAGGTTAATTCCGGTGAACC & AT3G23240 \\
\hline & & $\mathrm{R}$ & TCAACTTCCCGTITTCAGACGA & \\
\hline
\end{tabular}

\section{Histochemical analysis}

Reactive oxygen species (ROS) accumulation was determined as previously described [77]. Briefly, infected and control leaves were vacuum infiltrated with $0.1 \%(\mathrm{w} / \mathrm{v})$ Diaminobenzidine (DAB) (Sigma) $(\mathrm{pH} 3.9)$ for $3 \mathrm{~min}$ and repeated if not all leaves were infiltrated. Leaves were placed on a moist filter paper in a Petri dish under high humidity until a brown precipitate was observed $(3-5 \mathrm{~h})$ and cleared in $96 \%(\mathrm{v} / \mathrm{v})$ ethanol and then fixed with a solution of 3:1:1 ethanol/lactic acid/glycerol and observed under a light microscope (Zeiss Stemi 2000C mounted with Axiocam).

For necrotic lesions, leaves were stained with lactophenol-trypan blue solution [78] (20 mL phenol, 20 $\mathrm{mL}$ lactic acid, $40 \mathrm{~mL}$ glycerol, $20 \mathrm{~mL}$ water and $0.05 \%$ trypan blue mix and $200 \mathrm{~mL} 96 \%$ ethanol) for $2 \mathrm{~min}$ and de-stained in chloral hydrate $(2.5 \mathrm{~g}$ in $1 \mathrm{~mL}$ of $30 \%$ glycerol) overnight. Leaves were viewed under a Carl Zeiss Axio Scope A1 microscope equipped with interference or phase-contrast optics and digital camera. The lesion area for each sample was determined using the ImageJ software. The scale for images was input into the software and using the freehand tool, region of necrotic lesion was selected and measured (W.S. Rasband, National Institutes of Health; http://imagej.nih.gov/ij/).

Lignin deposition was determined as follows; MS stressed, and control leaves were destained in 100\% ethanol. Leaves were transferred into freshly prepared $2.5 \%(\mathrm{w} / \mathrm{v})$ phloroglucinol in $75 \%$ ethanol at room temperature and then mounted in $33 \% \mathrm{HCl}$ for $5 \mathrm{~min}$.

Callose deposition was determined by destaining leaves in $95-100 \%$ ethanol to remove chlorophyll. After $24 \mathrm{~h}$, leaves were washed in $0.07 \mathrm{M}$ phosphate $(\mathrm{pH} 9.0)$ buffer and then transferred into a new $0.07 \mathrm{M}$ phosphate buffer ( $\mathrm{pH}$ 9.0) containing $0.05 \%$ aniline blue (Sigma) for $2 \mathrm{~h}$ in the dark. Samples were visualized and photographed with Carl Zeiss Axio Scope A1 microscope equipped with fluorescent UV light (excitation 340 to $380 \mathrm{~nm}$, emission $425 \mathrm{~nm}$ ). The calculation of the aniline blue-emitted fluorescence of callose deposits was 
determine by using the ImageJ software (W.S. Rasband, National Institutes of Health; http://imagej.nih.gov/ij/). "The freehand selection tool" was used to define the area of callose deposit. Note, all images must have the same camera settings (scale/focal length and lightening) during capturing. For set measurement, the area integrated intensity and mean grey value were selected in program and the analyse tool ROI manager was used to select and measure several callose depositions per image. Background was selected for every image determined by area with no fluorescence to determine the corrected total fluorescence intensity for callose deposit.

\section{Phytohormone quantification}

For quantification of the endogenous JA hormone, the whole rosette was excised and quickly placed in liquid nitrogen and transferred to $-80{ }^{\circ} \mathrm{C}$ freezer for further analysis. Extraction of hormones was performed as previously described with modifications $[79,80]$ using the UPLC/ESI-MS/MS (Water, Milford, USA) at the Western Sydney University, Mass Spectrometry Facility, Campbelltown, Australia. The pure JA standard hormone was obtained from Sigma Aldrich. The internal standard- deuterated compound $\left[{ }^{2} \mathrm{H}_{4}\right]$-SA $\left(\mathrm{C}_{7} \mathrm{H}_{2} \mathrm{D}_{4} \mathrm{O}_{3}\right)$ was obtained from Olchemim Ltd., Olomouc, Czech Republic and the jasmonic- $\mathrm{d}_{5}$ acid $\left(\mathrm{C}_{12} \mathrm{H}_{13} \mathrm{D}_{5} \mathrm{O}_{3}\right)$ was obtained from CND isotopes, Canada. The whole plant was excised for analysis to reduce variation resulting from leaf age. In total, 1015 biological replicates each containing 2 plants were used for extraction.

Briefly, $200 \mathrm{mg}$ of fine power from tissue ground in liquid nitrogen was put in a $2 \mathrm{~mL}$ Eppendorf tube. 1 $\mathrm{mL}$ of extraction solvent (methanol: water: acetic acid, 69:30:1 (v/v/v) containing $100 \mathrm{ppb}$ final concentration of the internal standard (a labelled form of the compound ${ }^{2} \mathrm{H}_{4} \mathrm{SA},{ }^{2} \mathrm{H}_{2}$ JA) was added. The control (blank) contained extraction solvent with the internal standard without plant materials. Samples were vortex at $4{ }^{\circ} \mathrm{C}$ for $5 \mathrm{~min}$. After centrifugation $(10,000 \mathrm{rpm}$ for 15 min at $4{ }^{\circ} \mathrm{C}$ ), the supernatant was collected, and the pellet was re-extracted with $0.5 \mathrm{~mL}$ of extraction solvent and the extraction repeated twice. The upper organic layers collected, combined and evaporated to dryness under nitrogen gas. Each sample was resuspended in $250 \mu \mathrm{l}$ of methanol: water $(70: 30, \mathrm{v} / \mathrm{v})$ by ultrasonication for $15 \mathrm{~min}\left(4-8{ }^{\circ} \mathrm{C}\right)$ and filtered through a $0.22 \mu \mathrm{m}$ PTFE filter (Waters, Milford, MA, USA). Samples $(10 \mu \mathrm{l})$ were then analysed by UPLC/ ESI-MS/ MS. For the analysis of the extracts, a HALO $^{\text {im }}$ C18 (Advanced Materials Technology, Inc., Wilmington, USA $)$ column $(2.1 \times 75 \mathrm{~mm}, 2.7 \mu \mathrm{m})$ was used. A calibration curve was created for quantification containing each of the unlabelled analyte pure compounds (JA) from $1 \mathrm{ppb}$ to $200 \mathrm{ppb}$. To each standard solution, the same amount of internal standard was added. Calibration curve for each analyte was generated using MassLynx $4.1^{\text {tw }}$ software (Waters, USA).

\section{Statistical analysis}

Significant differences between control and MS plants were analysed using analysis of variance (ANOVA) according to Bonferroni post hoc test $(P<0.05)$ for more than 2 data sets, using SigmaPlot 14.0 software. On some data, where only 2 groups were compared, the Student's $t$-test was used. Error bars show standard error (SE).

\section{Abbreviations \\ MS: Mechanical stress; JA: Jasmonic acid; SA: Salicylic acid; TCH: Touch; WT: Wild type}

\section{Acknowledgments}

We thank Meena Mikhael and Emma Kuebler from the Western Sydney University Mass Spectrometry Facility for their technical support. Prof. Jimmy Botella provided homozygous coi1-21 mutant seeds. A Western Sydney University Southee scholarship was awarded to EB.

\section{Authors' contributions}

$\mathrm{CIC}$ and $\mathrm{EB}$ conceived ideas and designed research. EB performed experiments. EB wrote the manuscript, analysed data and prepared figures with assistance from primary supervisor CIC. Co-supervision of EB was provided by DT, ZC and AP. All authors edited the manuscript. The authors read and approved the final manuscript.

\section{Funding}

EB was supported by an International Australian Postgraduate Award scholarship through Western Sydney University. Western Sydney University provided research funding to undertake experimentation.

\section{Availability of data and materials}

The datasets used and/or analysed during the current study are available from the corresponding author on reasonable request. The datasets utilising genetic polymorphisms and DNA sequence information used in this study are available from TAIR [https://www.arabidopsis.org]

\section{Ethics approval and consent to participate}

Not applicable.

\section{Consent for publication}

Not applicable.

\section{Competing interests}

The authors declare that they have no competing interests.

\section{Author details}

${ }^{1}$ Hawkesbury Institute for the Environment, Western Sydney University, Locked Bag 1797, Penrith, NSW 2751, Australia. ${ }^{2}$ Present address: Department of Biochemistry, Cellular and Molecular Biology, University of Tennessee, Hesler Biology Building. 1441 Circle Drive, Knoxville, TN 37996, USA. ${ }^{3}$ School of Science, Western Sydney University, Penrith, NSW 2751, Australia.

Received: 2 June 2020 Accepted: 26 November 2020

Published online: 07 December 2020

\section{References}

1. lida H. Mugifumi, a beneficial farm work of adding mechanical stress by treading to wheat and barley seedlings. Front Plant Sci. 2014;5:453.

2. Braam J. In touch: plant responses to mechanical stimuli. New Phytol. 2005; 165(2):373-89. 
3. Telewski FW, Jaffe MJ. Thigmomorphogenesis - changes in the morphology and chemical-composition induced by mechanical perturbation in 6month-old Pinus-Taeda seedlings. Can J Forest Res Rev Canadienne De Recherche Forestiere. 1981;11(2):380-7.

4. Monshausen GB, Haswell ES. A force of nature: molecular mechanisms of mechanoperception in plants. J Exp Bot. 2013;64(15):4663-80.

5. Tretner C, Huth U, Hause B. Mechanostimulation of Medicago truncatula leads to enhanced levels of jasmonic acid. J Exp Bot. 2008;59(10):2847-56.

6. Tomas-Grau RH, Requena-Serra FJ, Hael-Conrad V, Martínez-Zamora MG, Guerrero-Molina MF, Díaz-Ricci JC. Soft mechanical stimulation induces a defense response against Botrytis cinerea in strawberry. Plant Cell Rep. 2018; 37(2):239-50.

7. Gus-Mayer S, Naton B, Hahlbrock K, Schmelzer E. Local mechanical stimulation induces components of the pathogen defense response in parsley. Proc Natl Acad Sci. 1998;95(14):8398-403.

8. Benikhlef L, L'Haridon F, Abou-Mansour E, Serrano M, Binda M, Costa A, Lehmann S, Métraux J-P. Perception of soft mechanical stress in Arabidopsis leaves activates disease resistance. BMC Plant Biol. 2013;13(1):1-12.

9. Van Moerkercke A, Duncan O, Zander M, Šimura J, Broda M, Vanden Bossche R, Lewsey MG, Lama S, Singh KB, Ljung K, et al. A MYC2/MYC3/ MYC4-dependent transcription factor network regulates water sprayresponsive gene expression and jasmonate levels. Proc Natl Acad Sci. 2019; 116(46):23345-56.

10. Lee D, Polisensky DH, Braam J. Genome-wide identification of touch- and darkness-regulated Arabidopsis genes: a focus on calmodulin-like and XTH genes. New Phytol. 2005;165(2):429-44.

11. Xu Y, Berkowitz O, Narsai R, De Clercq I, Hooi M, Bulone V, Van Breusegem F, Whelan J, Wang Y. Mitochondrial function modulates touch signalling in Arabidopsis thaliana. Plant J. 2019;97(4):623-45.

12. Pomiès L, Decourteix M, Franchel J, Moulia B, Leblanc-Fournier N. Poplar stem transcriptome is massively remodelled in response to single or repeated mechanical stimuli. BMC Genomics. 2017;18(1):300.

13. Gagliano M, Renton M, Depczynski M, Mancuso S. Experience teaches plants to learn faster and forget slower in environments where it matters. Oecologia. 2014;175(1):63-72.

14. Gagliano M, Vyazovskiy W, Borbely AA, Grimonprez M, Depczynski M. Learning by Association in Plants. Sci Rep. 2016;6:38427.

15. Leblanc-Fournier N, Martin L, Lenne C, Decourteix M. To respond or not to respond, the recurring question in plant mechanosensitivity. Front Plant Sci. 2014;5:401.

16. Chehab EW, Yao C, Henderson Z, Kim S, Braam J. Arabidopsis touchinduced morphogenesis is jasmonate mediated and protects against pests. Curr Biol. 2012;22(8):701-6.

17. Kazan K, Manners JM. MYC2: the master in action. Mol Plant. 2013;6(3):686703.

18. Zhang L, Zhang F, Melotto M, Yao J, He SY. Jasmonate signaling and manipulation by pathogens and insects. J Exp Bot. 2017;68(6):1371-85.

19. Lange MJP, Lange T. Touch-induced changes in Arabidopsis morphology dependent on gibberellin breakdown. Nat Plants. 2015;1:14025.

20. Li Z, Gong M. Mechanical stimulation-induced cross-adaptation in plants: an overview. J Plant Biol. 2011:54:358-64.

21. He Y, Li Z. Epigenetic environmental memories in plants: establishment, maintenance, and reprogramming. Trends Genet. 2018;34(11):856-66.

22. Cazzonelli Cl, Nisar N, Roberts AC, Murray KD, Borevitz JO, Pogson BJ. A chromatin modifying enzyme, SDG8, is involved in morphological, gene expression, and epigenetic responses to mechanical stimulation. Front Plant Sci. 2014:5:533.

23. Jensen GS, Fal K, Hamant O, Haswell ES. The RNA polymerase-associated factor 1 complex is required for plant touch responses. J Exp Bot. 2017; 68(3):499-511.

24. Mauch-Mani B, Baccelli I, Luna E, Flors V. Defense priming: an adaptive part of induced resistance. Annu Rev Plant Biol. 2017;68(1):485-512.

25. Avramova Z. Defence-related priming and responses to recurring drought: two manifestations of plant transcriptional memory mediated by the ABA and JA signalling pathways. Plant Cell Environ. 2019;42(3):983-97.

26. Hilker $M$, Schmülling T. Stress priming, memory, and signalling in plants. Plant Cell Environ. 2019;42(3):753-61.

27. Cho Y. How the Necrotrophic fungus Alternaria brassicicola kills plant cells remains an enigma. Eukaryot Cell. 2015;14(4):335-44.

28. Nowakowska M, Wrzesińska M, Kamiński P, Szczechura W, Lichocka M, Tartanus M, Kozik EU, Nowicki M. Alternaria brassicicola - Brassicaceae pathosystem: insights into the infection process and resistance mechanisms under optimized artificial bio-assay. Eur J Plant Pathol. 2019;153(1):131-51.

29. Thomma BPHJ, Eggermont K, Penninckx IAMA, Mauch-Mani B, Vogelsang R, Cammue BPA, Broekaert WF. Separate jasmonate-dependent and salicylatedependent defense-response pathways in Arabidopsis are essential for resistance to distinct microbial pathogens. Proc Natl Acad Sci. 1998;95(25): 15107-11.

30. Spanu PD, Panstruga R. Editorial: Biotrophic Plant-Microbe Interactions. Front Plant Sci. 2017:8:192.

31. Wright AJ, Knight $H$, Knight MR. Mechanically stimulated TCH3 gene expression in Arabidopsis involves protein phosphorylation and EIN6 downstream of calcium. Plant Physiol. 2002;128(4):1402-9.

32. Xu W, Purugganan MM, Polisensky DH, Antosiewicz DM, Fry SC, Braam J. Arabidopsis TCH4, regulated by hormones and the environment, encodes a xyloglucan endotransglycosylase. Plant Cell. 1995;7(10):1555-67.

33. Su'udi M, Kim MG, Park S-R, Hwang D-J, Bae S-C, Ahn I-P. Arabidopsis cell death in compatible and incompatible interactions with Alternaria brassicicola. Mol Cells. 2011;31(6):593-601.

34. van Wees SCM, Chang HS, Zhu T, Glazebrook J. Characterization of the early response of Arabidopsis to Alternaria brassicicola infection using expression profiling. Plant Physiol. 2003;132(2):606-17.

35. Kadota Y, Shirasu K, Zipfel C. Regulation of the NADPH Oxidase RBOHD during plant immunity. Plant Cell Physiol. 2015;56(8):1472-80.

36. Rossi FR, Krapp AR, Bisaro F, Maiale SJ, Pieckenstain FL, Carrillo N. Reactive oxygen species generated in chloroplasts contribute to tobacco leaf infection by the necrotrophic fungus Botrytis cinerea. Plant J. 2017;92(5): 761-73.

37. Wang Y, Ji D, Chen T, Li B, Zhang Z, Qin G, Tian S. Production, Signaling, and Scavenging Mechanisms of Reactive Oxygen Species in Fruit-Pathogen Interactions. Int J Mol Sci. 2019;20(12):2994.

38. Pathak RK, Baunthiyal M, Pandey N, Pandey D, Kumar A. Modeling of the jasmonate signaling pathway in Arabidopsis thaliana with respect to pathophysiology of Alternaria blight in Brassica. Sci Rep. 2017;7(1): 16790.

39. Feys B, Benedetti CE, Penfold CN, Turner JG. Arabidopsis mutants selected for resistance to the Phytotoxin Coronatine are male sterile, insensitive to methyl Jasmonate, and resistant to a bacterial pathogen. Plant Cell. 1994; 6(5):751-9.

40. Kim J, Dotson B, Rey C, Lindsey J, Bleecker AB, Binder BM, Patterson SE. New clothes for the jasmonic acid receptor COl1: delayed abscission, meristem arrest and apical dominance. PLoS One. 2013;8(4):e60505.

41. Hardham AR. Microtubules and biotic interactions. Plant J. 2013;75(2):27889.

42. Kesten C, Menna A, Sánchez-Rodríguez C. Regulation of cellulose synthesis in response to stress. Curr Opin Plant Biol. 2017:40:106-13.

43. Bacete L, Mélida H, Miedes E, Molina A. Plant cell wall-mediated immunity: cell wall changes trigger disease resistance responses. Plant J. 2018;93(4): 614-36

44. Voigt CA. Callose-mediated resistance to pathogenic intruders in plant defense-related papillae. Front Plant Sci. 2014;5:168.

45. Ellinger D, Naumann M, Falter C, Zwikowics C, Jamrow T, Manisseri C, Somerville SC, Voigt CA. Elevated early Callose deposition results in complete penetration resistance to powdery mildew in Arabidopsis. Plant Physiol. 2013;161(3):1433-44.

46. Voigt CA. Cellulose/callose glucan networks: the key to powdery mildew resistance in plants? New Phytol. 2016;212(2):303-5.

47. Chowdhury J, Schober MS, Shirley NJ, Singh RR, Jacobs AK, Douchkov D, Schweizer P, Fincher GB, Burton RA, Little A. Down-regulation of the glucan synthase-like 6 gene (HvGsl6) in barley leads to decreased callose accumulation and increased cell wall penetration by Blumeria graminis $\mathrm{f}$. $\mathrm{sp}$. hordei. New Phytol. 2016;212(2):434-43.

48. Raggi S, Ferrarini A, Delledonne M, Dunand C, Ranocha P, De Lorenzo G, Cervone F, Ferrari S. The Arabidopsis class III peroxidase AtPRX71 negatively regulates growth under physiological conditions and in response to Cell Wall damage. Plant Physiol. 2015;169(4):2513-25.

49. Chassot C, Buchala A, Schoonbeek HJ, Metraux JP, Lamotte O. Wounding of Arabidopsis leaves causes a powerful but transient protection against Botrytis infection. Plant J. 2008;55(4):555-67.

50. Lu D, Wang T, Persson S, Mueller-Roeber B, Schippers JHM. Transcriptional control of ROS homeostasis by KUODA1 regulates cell expansion during leaf development. Nat Commun. 2014;5:3767. 
51. Giri MK, Singh N, Banday ZZ, Singh V, Ram H, Singh D, Chattopadhyay S, Nandi AK. GBF1 differentially regulates CAT2 and PAD4 transcription to promote pathogen defense in Arabidopsis thaliana. Plant J. 2017;91(5):80215.

52. Glazebrook J, Ausubel FM. Isolation of phytoalexin-deficient mutants of Arabidopsis thaliana and characterization of their interactions with bacterial pathogens. Proc Natl Acad Sci. 1994;91(19):8955-9.

53. Khare D, Choi H, Huh SU, Bassin B, Kim J, Martinoia E, Sohn KH, Paek K-H, Lee $Y$. Arabidopsis ABCG34 contributes to defense against necrotrophic pathogens by mediating the secretion of camalexin. Proc Natl Acad Sci. 2017:114(28):E5712-20

54. Dubreuil-Maurizi C, Vitecek J, Marty L, Branciard L, Frettinger $P$, Wendehenne D, Meyer AJ, Mauch F, Poinssot B. Glutathione deficiency of the Arabidopsis mutant pad2-1 affects oxidative stress-related events, defense gene expression, and the hypersensitive response. Plant Physiol. 2011;157(4):2000-12

55. Marino D, Dunand C, Puppo A, Pauly N. A burst of plant NADPH oxidases. Trends Plant Sci. 2012;17(1):9-15.

56. Tsukagoshi H, Busch W, Benfey PN. Transcriptional regulation of ROS controls transition from proliferation to differentiation in the root. Cell. 2010; 143(4):606-16.

57. Glazebrook J. Contrasting mechanisms of defense against biotrophic and necrotrophic pathogens. Annu Rev Phytopathol. 2005;43:205-27.

58. Bömer M, O’Brien JA, Pérez-Salamó I, Krasauskas J, Finch P, Briones A, Daudi A, Souda P, Tsui T-L, Whitelegge JP, et al. COl1-dependent jasmonate signalling affects growth, metabolite production and cell wall protein composition in arabidopsis. Ann Bot. 2018;122(7):1117-29.

59. Westphal L, Scheel D, Rosahl S. The coi1-16 mutant harbors a second site mutation rendering PEN2 nonfunctional. Plant Cell. 2008;20(4):824-6.

60. Yun HS, Kang BG, Kwon C. Arabidopsis immune secretory pathways to powdery mildew fungi. Plant Signal Behav. 2016;11(10):e1226456.

61. Ndamukong I, Abdallat AA, Thurow C, Fode B, Zander M, Weigel R, Gatz C. SA-inducible Arabidopsis glutaredoxin interacts with TGA factors and suppresses JA-responsive PDF1.2 transcription. Plant J. 2007;50(1):128-39.

62. Huang H, Liu B, Liu L, Song S. Jasmonate action in plant growth and development. J Exp Bot. 2017;68(6):1349-59.

63. Li X, Liu F. Drought Stress Memory and Drought Stress Tolerance in Plants: Biochemical and Molecular Basis. In: Hossain MA, Wani SH, Bhattacharjee S, Burritt DJ, Tran L-SP, editors. Drought Stress Tolerance in Plants, Vol 1: Physiology and Biochemistry. Cham: Springer International Publishing; 2016. p. 17-44.

64. Feng XJ, Li JR, Qi SL, Lin QF, Jin JB, Hua XJ. Light affects salt stress-induced transcriptional memory of P5CS1 in Arabidopsis. Proc Natl Acad Sci. 2016; 113(51):E8335-43.

65. Lämke J, Bäurle I. Epigenetic and chromatin-based mechanisms in environmental stress adaptation and stress memory in plants. Genome Biol. 2017:18(1):124

66. Martin L, Leblanc-Fournier N, Julien J-L, Moulia B, Coutand C. Acclimation kinetics of physiological and molecular responses of plants to multiple mechanical loadings. J Exp Bot. 2010;61(9):2403-12.

67. Klepikova AV, Logacheva MD, Dmitriev SE, Penin AA. RNA-seq analysis of an apical meristem time series reveals a critical point in Arabidopsis thaliana flower initiation. BMC Genomics. 2015:16:466.

68. Dennis ES, Peacock WJ. Epigenetic regulation of flowering. Curr Opin Plant Biol. 2007;10(5):520-7.

69. Berr A, McCallum EJ, Alioua A, Heintz D, Heitz T, Shen W-H. Arabidopsis histone methyltransferase SET DOMAIN GROUP8 mediates induction of the Jasmonate/ethylene pathway genes in plant defense response to Necrotrophic fungi. Plant Physiol. 2010;154(3):1403-14.

70. Soppe WJ, Bentsink L, Koornneef M. The early-flowering mutant efs is involved in the autonomous promotion pathway of Arabidopsis thaliana. Development. 1999;126(21):4763-70.

71. Liu X, Hou X. Antagonistic regulation of ABA and GA in metabolism and signaling pathways. Front Plant Sci. 2018;9:251.

72. Trusov Y, Sewelam N, Rookes JE, Kunkel M, Nowak E, Schenk PM, Botella JR. Heterotrimeric $\mathrm{G}$ proteins-mediated resistance to necrotrophic pathogens includes mechanisms independent of salicylic acid-, jasmonic acid/ethyleneand abscisic acid-mediated defense signaling. Plant J. 2009;58(1):69-81.

73. Yan J, Zhang C, Gu M, Bai Z, Zhang W, Qi T, Cheng Z, Peng W, Luo H, Nan $F$, et al. The Arabidopsis CORONATINE INSENSITIVE1 protein is a jasmonate receptor. Plant Cell. 2009;21(8):2220-36.
74. Ellis C, Turner JG. A conditionally fertile coi1 allele indicates cross-talk between plant hormone signalling pathways in Arabidopsis thaliana seeds and young seedlings. Planta. 2002;215(4):549-56.

75. Li G, Zhang X, Wan D, Zhang S, Xia Y. Methods for Analysis of Disease Resistance and the Defense Response in Arabidopsis. In: Running PM, editor. G Protein-Coupled Receptor Signaling in Plants: Methods and Protocols. Totowa: Humana Press; 2013. p. 55-66.

76. Pfaffl MW. A new mathematical model for relative quantification in real-time RT-PCR. Nucleic Acids Res. 2001:29(9):e45.

77. Jambunathan N. Determination and Detection of Reactive Oxygen Species (ROS), Lipid Peroxidation, and Electrolyte Leakage in Plants. In: Sunkar R, editor. Plant Stress Tolerance: Methods and Protocols. Totowa: Humana Press; 2010. p. 291-7.

78. Brenya E, Trusov Y, Dietzgen RG, Botella JR. Heterotrimeric G-proteins facilitate resistance to plant pathogenic viruses in Arabidopsis thaliana (L.) Heynh. Plant Signal Behav. 2016;11(8):e1212798.

79. Müller M, Munné-Bosch S. Rapid and sensitive hormonal profiling of complex plant samples by liquid chromatography coupled to electrospray ionization tandem mass spectrometry. Plant Methods. 2011;7(1):37.

80. Almeida Trapp M, De Souza GD, Rodrigues-Filho E, Boland W, Mithöfer A. Validated method for phytohormone quantification in plants. Front Plant Sci. 2014;5:417.

\section{Publisher's Note}

Springer Nature remains neutral with regard to jurisdictional claims in published maps and institutional affiliations.
Ready to submit your research? Choose BMC and benefit from:

- fast, convenient online submission

- thorough peer review by experienced researchers in your field

- rapid publication on acceptance

- support for research data, including large and complex data types

- gold Open Access which fosters wider collaboration and increased citations

- maximum visibility for your research: over $100 \mathrm{M}$ website views per year

At $\mathrm{BMC}$, research is always in progress.

Learn more biomedcentral.com/submissions 